\title{
Plasma angiopoietin-2 is associated with age-related deficits in cognitive sub-scales in Ugandan children following severe malaria
}

Benson J. Ouma', Paul Bangirana², John M. Ssenkusu³ , Dibyadyuti Datta ${ }^{4}$, Robert O. Opoka ${ }^{5}$, Richard Idro ${ }^{5,6}$, Kevin C. Kain ${ }^{7}$, Chandy C. John ${ }^{4}$ and Andrea L. Conroy ${ }^{4^{*}}$ (1)

\begin{abstract}
Background: Elevated angiopoietin-2 (Angpt-2) concentrations are associated with worse overall neurocognitive function in severe malaria survivors, but the specific domains affected have not been elucidated.

Methods: Ugandan children with severe malaria underwent neurocognitive evaluation a week after hospital discharge and at 6,12 and 24 months follow-up. The relationship between Angpt-2 concentrations and age-adjusted, cognitive sub-scale $z$-scores over time were evaluated using linear mixed effects models, adjusting for disease severity (coma, acute kidney injury, number of seizures in hospital) and sociodemographic factors (age, gender, height-for-age z-score, socio-economic status, enrichment in the home environment, parental education, and any preschool education of the child). The Mullen Scales of Early Learning was used in children $<5$ years and the Kaufman Assessment Battery for Children 2nd edition was used in children $\geq 5$ years of age. Angpt-2 levels were measured on admission plasma samples by enzyme-linked immunosorbent assay. Adjustment for multiple comparisons was conducted using the Benjamini-Hochberg Procedure of False Discovery Rate.
\end{abstract}

Results: Increased admission Angpt-2 concentration was associated with worse outcomes in all domains (fine and gross motor, visual reception, receptive and expressive language) in children $<5$ years of age at the time of severe malaria episode, and worse simultaneous processing and learning in children $<5$ years of age at the time of severe malaria who were tested when $\geq 5$ years of age. No association was seen between Angpt- 2 levels and cognitive outcomes in children $\geq 5$ years at the time of severe malaria episode, but numbers of children and testing time points were lower for children $\geq 5$ years at the time of severe malaria episode.

Conclusion: Elevated Angpt-2 concentration in children with severe malaria is associated with worse outcomes in multiple neurocognitive domains. The relationship between Angpt-2 and worse cognition is evident in children $<5$ years of age at the time of severe malaria presentation and in selected domains in older years.

Keywords: Angiopoietin-2, Severe malaria, Cognition, Children

*Correspondence: conroya@iu.edu

${ }^{4}$ Ryan White Center for Pediatric Infectious Disease and Global Health, Indiana University School of Medicine, Indianapolis, IN, USA

Full list of author information is available at the end of the article

\section{Background}

Plasmodium falciparum accounts for significant global mortality, with an estimated 228 million cases and 405,000 deaths reported in 2018 [1]. Severe malaria is a leading cause of acquired neurodisability in African children [2]. Clinical complications associated with worse cognitive outcomes in severe malaria include coma [3], 
multiple convulsions [3], severe anaemia [4] and acute kidney injury (AKI) [5].

The angiopoietin-Tie-2 pathway is a critical regulator of endothelial and blood-brain-barrier integrity [6]. Angiopoietin (Angpt)-2 is rapidly released from activated endothelium where it inhibits Angpt-1 mediated phosphorylation of Tie-2, sensitizing endothelium to TNF, increasing expression of cellular adhesion molecules, and promoting vascular permeability $[7,8]$. There is emerging evidence of Angpt-2 destabilizing endothelium through Tie-2 independent integrin-signalling leading to astrocyte and pericyte apoptosis $[9,10]$. Elevated Angpt-2 is well described in severe $P$. falciparum and associated with disease severity [11-21] and mortality [11, 15-19, 21]. A relationship between elevated Angpt-2 levels and reduced cognitive function in survivors was previously reported using a summary variable that took into account multiple specific domains of cognitive and motor function [21]. It is important to know the specific cognitive and motor domains associated with elevated Angpt-2 levels, as this gives a more precise idea of brain areas affected, and areas in which to look for improvement after interventions to decrease Angpt-2 levels. For this reason, additional analyses were conducted to evaluate the relationship between Angpt-2 levels and individual cognitive and motor domains in children who survived severe malaria. Since cognitive assessment tools differ in children $<5$ years of age compared to children $\geq 5$ years of age, analyses are presented stratified by age.

\section{Methods}

\section{Study design}

Children aged 18 months to 12 years were prospectively enrolled between 2008 and 2013 at Mulago National Referral and Teaching Hospital in Kampala, Uganda in a study evaluating cognitive function after two major forms of severe malaria: cerebral malaria $(\mathrm{CM})$ or severe malarial anaemia (SMA) [4]. All children with severe malaria had $P$. falciparum identified by blood smear and met case definitions for CM (Blantyre Coma Score $\leq 2$; P. falciparum on blood smear; no known cause of coma) or SMA (P. falciparum on blood smear; haemoglobin level $\leq 5 \mathrm{~g}$ / dL) [4]. Exclusion criteria for all children included known chronic illness (including sickle cell anaemia) requiring medical care; known developmental delay; or, prior history of coma, head trauma, hospitalization for malnutrition, or cerebral palsy. Community children (CC) were enrolled to generate population-specific, age-adjusted, cognitive $\mathrm{z}$-scores. Additional exclusion criteria for $\mathrm{CC}$ included the following: illness requiring medical care within the previous 4 weeks; or, major medical or neurological abnormalities on screening physical examination. Children were enrolled if they met criteria for $\mathrm{CM}$ or SMA, but were also assessed for other severe malaria criteria, including deep breathing, repeated convulsions ( $\geq 2$ convulsions), prostration, shock, bleeding, jaundice, hypoglycaemia (glucose $<2.2 \mathrm{mmol} / \mathrm{L}$ ), lactic acidosis (lactate $>5 \mathrm{mmol} / \mathrm{L}$ ), AKI (defined using the Kidney Disease: Improving Global Outcomes guidelines) [22], and hyperparasitaemia (parasitaemia $>250,000$ parasites $/ \mathrm{uL}$ ) [23]. Admission plasma samples were stored at $-80{ }^{\circ} \mathrm{C}$. Angpt-2 was measured by ELISA in EDTA anti-coagulated plasma samples (DuoSet, R\&D Systems, Minneapolis, MN, USA) [21].

All children underwent a medical history, physical examination and laboratory testing on enrolment. Emotional stimulation in the home was measured using ageappropriate versions of the Home Observation for the Measurement of the Environment [24]. Socio-economic status was measured as previously described [25].

\section{Cognitive assessments}

Children with severe malaria had cognition assessed one week after discharge and at 6,12 and 24 months followup by trained neuropsychological testers. Age-adjusted $\mathrm{z}$-scores for cognitive outcomes were computed using the scores of the reference population of $\mathrm{CC}$ as previously described (4). Z-scores have average of 0 and SD 1 in the reference population over all time points. Over the course of the study 132 children crossed age groups and switched from being tested with tools designed for children $<5$ years of age to tools designed for children $\geq 5$ years of age.

In children $<5$ years of age cognition was assessed using the Mullen Scales of Early Learning (MSEL), which measures gross motor functions, visual reception, fine motor skills, receptive language, and expressive language [26]. The four cognitive scales (visual reception, fine motor, receptive language, expressive language) are combined to generate the early learning composite which is a measure of cognitive ability. All five cognitive scales were assessed in this study. The fine motor scale assesses visual motor ability. The visual reception scale measures performance in processing visual patterns, in particular visual processing and visual memory. The receptive language scale measures a child's ability to process linguistic input, mainly in auditory comprehension and auditory memory. The expressive language scale measures the child's ability to use language productively through speaking ability and language formation. In children $\geq 5$ years, cognition was assessed using the Kaufman Assessment Battery for Children, 2nd edition (KABC-2) [27] and the sub-scales evaluated were planning (executive reasoning), learning (immediate and delayed memory), sequential processing (short-term memory) and simultaneous processing (visual-spatial processing and problem solving). The 
MSEL [4] and KABC-2 [28] have been used in Ugandan children.

\section{Statistical analysis}

Data were analysed using Stata v14.0 (StataCorp. 2015) and GraphPad Prism v7.03. Data were presented as mean (standard deviation, SD) or median (interquartile range, IQR) as indicated. Differences in median levels of Angpt-2 across age groups were evaluated using the Wilcoxon rank-sum test. Linear mixed effects modelling was used to assess the association between Angpt-2 and longitudinal changes in cognitive $\mathrm{z}$-scores where observations within subject were correlated using a subjectspecific intercept, and time points treated as categorical variables [21]. Models adjusted for age, gender, heightfor-age $\mathrm{z}$-scores, socio-economic status, enrichment in the home environment, parental education, preschool education, and disease severity on admission (presence of coma, number of convulsions, AKI) [21]. Adjustment for multiple comparisons was conducted using the Benjamini-Hochberg Procedure of False Discovery Rate.

\section{Results}

\section{Demographic characteristics of the study population} of children with severe malaria

A description of the 384 children included in the analysis is shown in Fig. 1. A description of the characteristics of the population, including the $\mathrm{CC}$, have been described previously [4]. Overall, the median age of children enrolled in the study was 3.31 (IQR, 2.29 to 4.75 ) years of age and $60.4 \%$ of children were male. The prevalence of HIV was $2.4 \%(n=9 / 382)$ and $4.2 \%(n=16 / 384)$ of children with severe malaria had sickle cell anaemia diagnosed by genotyping after study completion [29]. The demographic characteristics and frequency of severe malaria complications in the population stratified by age at enrolment are shown in Table 1 . There were no differences in median Angpt-2 levels at admission in children based on age group ( $<5$ years or $\geq 5$ years $)(p=0.451$, Table 1).

During the study period, 132 children $<5$ years of age at the time of the severe malaria episode crossed into the older age group and 129 were subsequently tested using the KABC-2 (Fig. 1, Table 1). The age stratification in this study reflects the age range of the cognitive assessment tools and the age-adjusted $\mathrm{z}$-scores for each cognitive and motor domain are presented in Table 2. There were 89 children $\geq 5$ years of age at enrolment who were exclusively tested with the KABC-2 over follow-up. The number of children crossing age groups at each time point is depicted in Fig. 1.

\section{Angiopoietin-2 and cognitive sub-scales in survivors} of severe malaria $<5$ years of age at the time of the severe malaria episode

To evaluate the relationship between Angpt- 2 and cognition, Angpt-2 levels at admission were compared to MSEL scores at any time point and to KABC-2 scores at any time point in which testing was done in the same child. In children $<5$ years of age at the time of severe malaria episode, increased Angpt-2 levels were associated with worse cognitive scores in all domains tested (Table 3). The strongest association between increased Angpt-2 and worse $\mathrm{z}$-scores for any cognitive domain was seen for visual reception $(\beta, 95 \%$ CI $-0.41,-0.67$ to -0.15$)$ followed by expressive language $(\beta, 95 \% \mathrm{CI}$ $-0.32,-0.56$ to -0.07$)$, fine motor skills $(\beta, 95 \% \mathrm{CI}$ $-0.30,-0.53$ to -0.06$)$ and receptive language $(\beta, 95 \%$ CI $-0.31,-0.56$ to -0.06$)$.

\section{Angiopoietin-2 and cognitive sub-scales in survivors of severe malaria based on clinical syndrome at presentation}

To evaluate whether the relationship between Angpt-2 and cognitive outcomes was affected by the presence of neurological complications on admission, analyses were stratified based on the study group: CM or SMA (Table 4). Angpt-2 levels were associated with worse cognitive scores in multiple domains in children $<5$ years of age at the time of severe malaria with worse $\mathrm{z}$-scores in fine motor skills, receptive language and visual reception in children with SMA and worse $\mathrm{z}$-scores in gross motor skills, receptive and expressive language, and visual reception in children with CM (Table 4). There was a trend towards persistent differences in learning in children $<5$ years of age at the time of severe malaria episode who were subsequently tested using the KABC-2 in children with CM (Table 4). However, there was limited power to detect differences in children $\geq 5$ years of age tested using the $\mathrm{KABC}-2$, especially after stratifying by study group on admission.

\section{Angiopoietin-2 and cognitive sub-scales in survivors of severe malaria in children $\geq 5$ years of age at time of severe malaria episode}

Another critical question is whether there is an age-specific window of susceptibility between Angpt- 2 and cognition based on the child's age at the time of the severe malaria admission. The data from the MSEL, presented above, showed associations of elevated Angpt- 2 with worse scores in multiple domains in children $<5$ years of age at time of severe malaria episode, and the effects persisted with differences in learning and simultaneous 


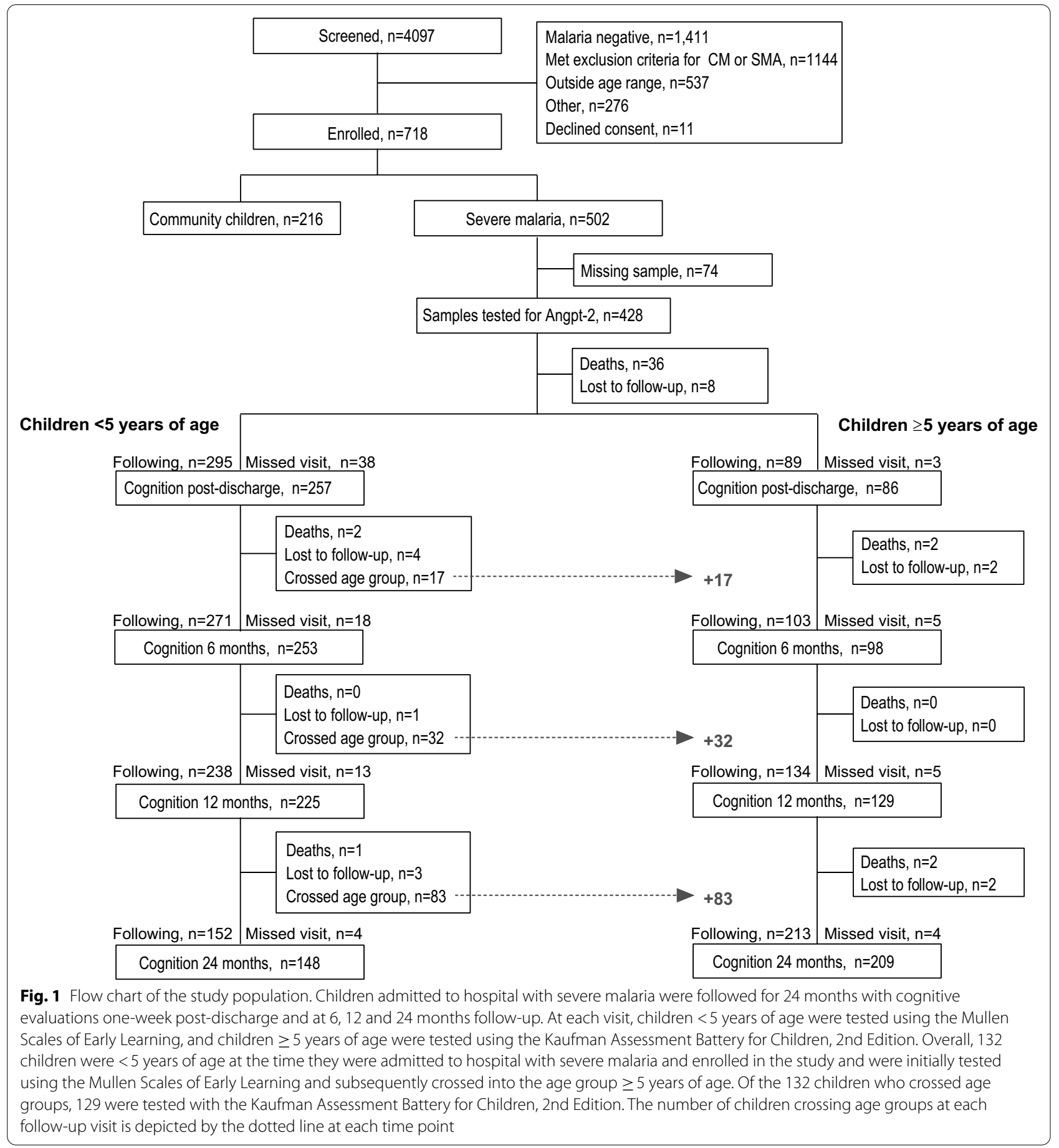

processing as children crossed age groups and were tested using the KABC-2 (Table 3 ).

The KABC-2 analysis was repeated in 89 children who were $\geq 5$ years of age at study enrolment (Table 5 ). In children $\geq 5$ years at the time of the severe malaria episode, there were no significant relationships between Angpt-2 and cognitive sub-scales ( $>0.05$ for all, Table 5 ).

\section{Discussion}

In this study, elevated Angpt-2 levels in Ugandan children with severe malaria were associated with lower z-scores over two-years follow-up in visual reception, fine motor development, and receptive and expressive language in children $<5$ years of age at the time of testing, and in lower learning and simultaneous processing 
Table 1 Characteristics of children with severe malaria based on age at first cognitive assessment

\begin{tabular}{|c|c|c|}
\hline & Children $<5$ years $(n=295)$ & $\begin{array}{l}\text { Children } \geq 5 \text { years } \\
\text { of age }(n=89)\end{array}$ \\
\hline \multicolumn{3}{|l|}{ Admission characteristics } \\
\hline Age (years), mean (SD) & $2.9(0.9)$ & $6.5(1.6)$ \\
\hline Gender (male), n (\%) & $172(58.3)$ & $60(67.4)$ \\
\hline Weight-for-age z-score, mean (SD) & $-1.2(1.1)$ & $-1.1(1.0)$ \\
\hline Height-for-age z-score, mean (SD) & $-1.3(1.5)$ & $-0.8(1.2)$ \\
\hline Socio-economic status, mean (SD) & $9.1(3.0)$ & $10.1(3.2)$ \\
\hline HOME z-score, mean (SD) & $-0.08(1.04)$ & $-0.08(0.88)$ \\
\hline \multicolumn{3}{|l|}{ Maternal education, n (\%) } \\
\hline Primary 6 or lower & $114(38.6)$ & $29(32.6)$ \\
\hline Primary 7 & $63(21.4)$ & $20(22.5)$ \\
\hline Secondary or higher & $109(37.0)$ & $36(40.5)$ \\
\hline Unknown & $9(3.1)$ & $4(4.5)$ \\
\hline \multicolumn{3}{|l|}{ Paternal education, n (\%) } \\
\hline Primary 6 or lower & $62(21.0)$ & $10(11.2)$ \\
\hline Primary 7 & $44(14.9)$ & $18(20.2)$ \\
\hline Secondary or higher & $133(45.1)$ & $41(46.1)$ \\
\hline Unknown & $56(19.0)$ & $20(22.5)$ \\
\hline HIV infected, n (\%) & $6(2.1)$ & $3(3.4)$ \\
\hline \multicolumn{3}{|l|}{ Sickle cell status, n (\%) } \\
\hline $\mathrm{HbAA}$ & $286(97.3)$ & $78(87.6)$ \\
\hline $\mathrm{HbAS}$ & $2(0.7)$ & $1(1.1)$ \\
\hline $\mathrm{HbSS}$ & $6(2.0)$ & $10(11.2)$ \\
\hline \multicolumn{3}{|l|}{ Admission severe malaria criteria } \\
\hline Cerebral malaria, n (\%) & $145(49.2)$ & $52(58.4)$ \\
\hline Deep breathing, n (\%) & $19(6.4)$ & $2(2.3)$ \\
\hline Repeated convulsions, n (\%) & $102(34.6)$ & $27(30.3)$ \\
\hline Prostration, n (\%) & $215(72.9)$ & $63(70.8)$ \\
\hline Shock, n (\%) & - & - \\
\hline Bleeding, n (\%) & $2(0.7)$ & $1(1.1)$ \\
\hline Jaundice, n (\%) & $197(66.8)$ & $51(57.3)$ \\
\hline Severe malarial anaemia, n (\%) & $187(63.4)$ & $40(44.9)$ \\
\hline Hypoglycaemia on admission, n (\%) & $19(6.6)$ & $1(1.2)$ \\
\hline Lactic acidosis, n (\%) & $117(42.2)$ & $19(24.1)$ \\
\hline Acute kidney injury, n (\%) & $102(34.6)$ & $28(31.5)$ \\
\hline Hyperparasitaemia, n (\%) & $54(19.0)$ & $12(13.6)$ \\
\hline Number of SM criteria present, mean (SD) & $3.9(1.6)$ & $3.3(1.2)$ \\
\hline Neurocognitive follow-up visits, $\mathrm{n}$ tested & Children $<5$ years & Children $\geq 5$ years \\
\hline One week post-discharge, $\mathrm{n}$ tested & 257 & 86 \\
\hline Six months follow-up, $\mathrm{n}$ tested & 253 & 98 \\
\hline 12 months follow-up, $\mathrm{n}$ tested & 225 & 129 \\
\hline 24 months follow-up, $\mathrm{n}$ tested & 148 & 209 \\
\hline Total for any follow-up visits, $\mathrm{n}$ tested & 295 & 218 \\
\hline Admission Angpt-2 (median, IQR), ng/mL & $1.78(0.99,3.13)$ & $1.65(0.84,3.06)$ \\
\hline
\end{tabular}

Data presented as mean (standard deviation), or $\mathrm{n}(\%)$ unless otherwise indicated 
Table 2 Mean age-adjusted z-scores across time points in children with Angpt-2 levels measured at admission

\begin{tabular}{|c|c|c|c|c|c|c|c|c|c|}
\hline \multirow{2}{*}{$\begin{array}{l}\text { Follow-up } \\
\text { assessment }\end{array}$} & \multicolumn{5}{|c|}{ Age adjusted $z$-scores for children $<5$ years of age } & \multicolumn{4}{|c|}{ Age adjusted $z$-scores for children $\geq 5$ years of age } \\
\hline & $\mathrm{Fi}$ & Gro & $\begin{array}{l}\text { Receptive } \\
\text { language }\end{array}$ & $\begin{array}{l}\text { Expressive } \\
\text { language }\end{array}$ & $\begin{array}{l}\text { isual } \\
\text { eception }\end{array}$ & g & Lea & & $\begin{array}{l}\text { imultaneous } \\
\text { rocessing }\end{array}$ \\
\hline I ween & 09) & -0.78 & $-0.67(1.22)$ & -0.07 & .20) & 89) & 197) & & 96) \\
\hline 6 months & $-0.56(0.99)$ & $-0.53(1.25)$ & $-0.63(1.13)$ & $-0.63(1.06)$ & 14) & 96) & $-0.13(1.07)$ & -0 & 1.12) \\
\hline 12 months & $-0.47(1.08)$ & $-0.36(1.21)$ & $-0.58(1.05)$ & $-0.64(1.10)$ & $-0.64(1.19)$ & $0.14(1.02)$ & $-0.10(1.06)$ & $-0.26(1.24)$ & $0.07(1.18)$ \\
\hline 24 months & $-0.40(0.91)$ & $-0.12(0.94)$ & $-0.72(0.92)$ & $-0.62(0.98)$ & $-0.49(1.20)$ & $0.14(0.75)$ & $-0.29(1.09)$ & $-0.38(1.25)$ & $-0.21(1.02)$ \\
\hline
\end{tabular}

Data presented are mean (SD) of age-adjusted z-scores

Table 3 Association between Angpt-2 level and longitudinal age-adjusted cognitive z-scores over two years follow-up in children with a severe malaria episode at $<5$ years of age

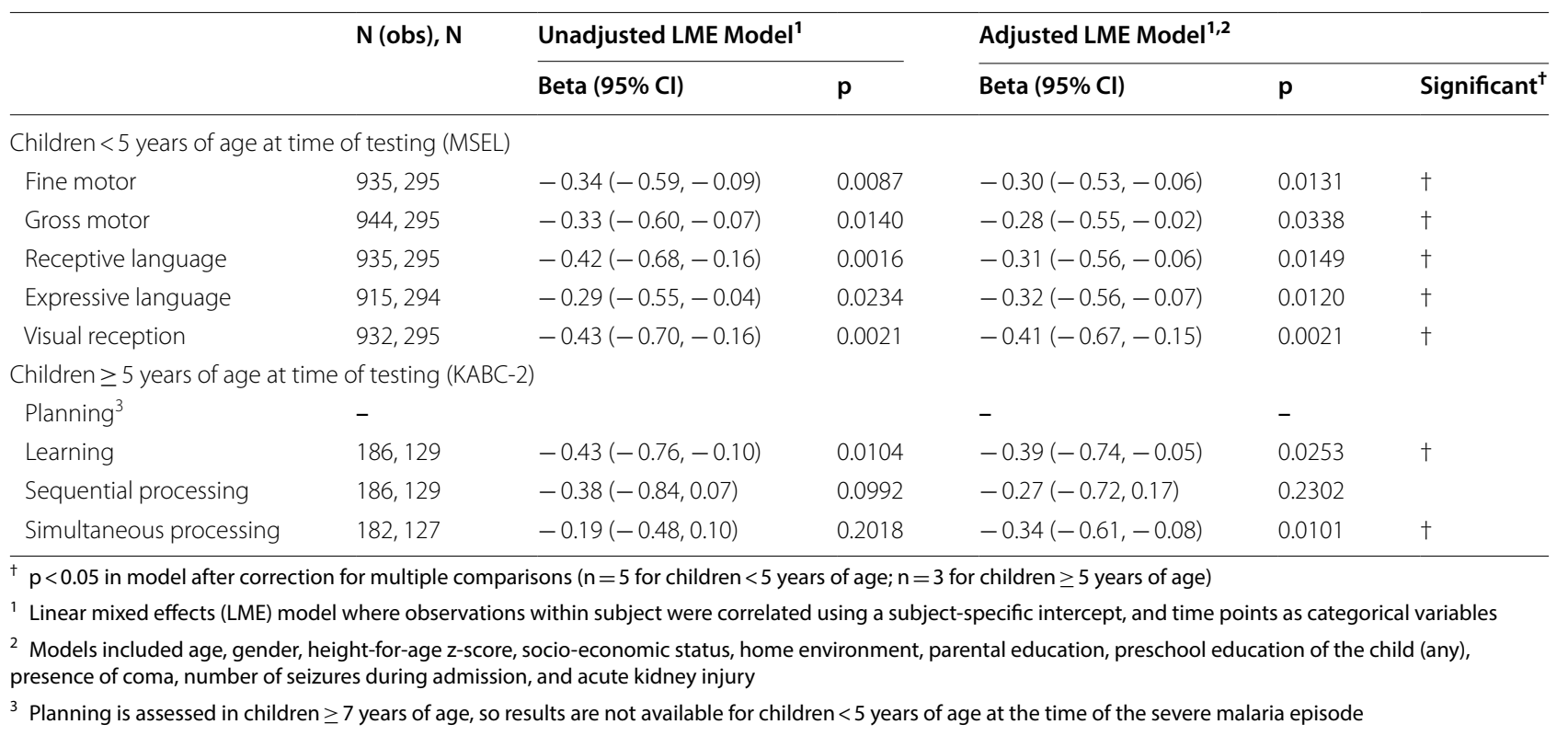

$\mathrm{z}$-scores in children $\geq 5$ years of age at the time of testing, but the latter associations are seen only in children $<5$ years of age at the time of the severe malaria episode. These results suggest that Angpt-2 is associated with worse cognitive scores in multiple domains in children with severe malaria who are $<5$ years of age at time of severe malaria, and these problems persist into older age, but that Angpt-2 is not associated with worse cognitive outcomes in any domain in children who are $\geq 5$ years of age at the time of severe malaria infection.

Assessment of the effects of age on the relationship to cognitive outcomes is made more difficult by the change in age status of many children over followup, such that a number of children initially tested at $<5$ years with the MSEL became 5 years of age during the study and switched to testing with the KABC-2. Thus, the results for the MSEL testing are from children who were all under 5 years at the time of severe malaria episode, while the results for $\mathrm{KABC}-2$ testing include both children who were $<5$ years at the time of severe malaria exposure as well as children $\geq 5$ years at the time of severe malaria exposure. Further analysis of relationships between Angpt-2 and KABC-2 based on child age at malaria exposure showed the relationships between Angpt-2 and poorer learning and simultaneous processing was driven by children $<5$ years of age at enrolment. There were no significant associations between Angpt-2 and KABC-2 results in children already $\geq 5$ years at enrolment. Although the number of children $\geq 5$ years at enrolment $(n=89)$ was lower than the number of children $<5$ years of age at enrolment who subsequently became 5 years of age $(n=129)$ and were tested by the KABC-2, this does not seem to be the primary explanation for the lack of association in older children, as effect sizes were lower in children 
Table 4 Association between Angpt-2 level and longitudinal age-adjusted cognitive z-scores over two years follow-up in children based on the severe malaria group at presentation in children $<5$ years of age

\begin{tabular}{|c|c|c|c|c|c|c|c|c|}
\hline & \multicolumn{4}{|c|}{ Adjusted LME estimates in SMA ${ }^{1,2}$} & \multicolumn{4}{|c|}{ Adjusted LME estimates in $\mathrm{CM}^{1,2}$} \\
\hline & $\mathrm{N}$ (obs), $\mathrm{N}$ & Beta $(95 \% \mathrm{Cl})$ & $\mathbf{P}$ & Significant $\dagger$ & $\mathrm{N}$ (obs), $\mathrm{N}$ & Beta $(95 \% \mathrm{Cl})$ & $\mathbf{P}$ & Significant $\dagger$ \\
\hline \multicolumn{9}{|c|}{ Children $<5$ years of age at time of testing (MSEL) } \\
\hline Fine motor & 476,148 & $-0.34(-0.58,-0.09)$ & 0.0078 & $\dagger$ & 459,147 & $-0.35(-0.79,0.08)$ & 0.110 & \\
\hline Gross motor & 484,148 & $-0.25(-0.57,0.08)$ & 0.132 & & 460,147 & $-0.51(-0.95,-0.07)$ & 0.0229 & $\dagger$ \\
\hline Receptive language & 480,148 & $-0.40(-0.69,-0.10)$ & 0.0096 & $\dagger$ & 455,147 & $-0.55(-0.98,-0.11)$ & 0.0141 & $\dagger$ \\
\hline Expressive language & 470,148 & $-0.23(-0.51,0.06)$ & 0.116 & & 445,146 & $-0.65(-1.07,-0.23)$ & 0.0029 & $\dagger$ \\
\hline Visual reception & 479,148 & $-0.38(-0.70,-0.05)$ & 0.0235 & $\dagger$ & 453,147 & $-0.65(-1.09,-0.21)$ & 0.0043 & $\dagger$ \\
\hline \multicolumn{9}{|c|}{ Children $\geq 5$ years of age at time of testing (KABC-2) } \\
\hline Planning $^{3}$ & - & & & & & - & - & \\
\hline Learning & 139,36 & $0.02(-0.62,0.67)$ & 0.9404 & & 204,53 & $-0.63(-1.35,0.10)$ & 0.0880 & \\
\hline Sequential processing & 139,36 & $0.09(-0.83,1.02)$ & 0.8339 & & 205,53 & $0.05(-0.84,0.93)$ & 0.9176 & \\
\hline Simultaneous processing & 138,36 & $-0.43(-1.13,0.27)$ & 0.2192 & & 205,53 & $-0.25(-0.96,0.46)$ & 0.4759 & \\
\hline \multicolumn{9}{|c|}{${ }^{\dagger} \mathrm{p}<0.05$ in model after correction for multiple comparisons $(\mathrm{n}=5$ for children $<5$ years of age; $\mathrm{n}=3$ for children $\geq 5$ years of age) } \\
\hline \multicolumn{9}{|c|}{${ }^{1}$ Linear mixed effects (LME) model where observations within subject were correlated using a subject-specific intercept, and time-points as categorical variables } \\
\hline \multicolumn{9}{|c|}{$\begin{array}{l}2 \text { Models included age, gender, height-for-age z-score, socio-economic status, home environment, parental education, preschool education of the child (any), } \\
\text { number of seizures during admission, and acute kidney injury }\end{array}$} \\
\hline
\end{tabular}

Table 5 Association between Angpt-2 level and longitudinal age-adjusted z scores over two years follow-up in children with a severe malaria episode at $\geq 5$ years of age

\begin{tabular}{|c|c|c|c|c|c|}
\hline & \multirow[t]{2}{*}{$\mathrm{N}$ (obs), $\mathrm{N}$} & \multicolumn{2}{|c|}{ Unadjusted LME Model $^{1}$} & \multicolumn{2}{|c|}{ Adjusted LME Model $^{1,2}$} \\
\hline & & Beta $(95 \% \mathrm{Cl})$ & $\mathbf{P}$ & Beta $(95 \% \mathrm{Cl})$ & Significant $†$ \\
\hline \multicolumn{6}{|c|}{ Children $\geq 5$ years of age at time of severe malaria episode (enrolment time point) (KABC-2) } \\
\hline Planning $^{3}$ & 194,84 & $-0.13(-0.42,0.16)$ & 0.3783 & $-0.16(-0.52,0.20)$ & 0.3844 \\
\hline Learning & 343,89 & $-0.22(-0.63,0.18)$ & 0.2764 & $-0.26(-0.72,0.20)$ & 0.2682 \\
\hline Sequential processing & 344,89 & $-0.10(-0.60,0.40)$ & 0.6967 & $-0.01(-0.59,0.56)$ & 0.9644 \\
\hline Simultaneous processing & 343,89 & $-0.21(-0.59,0.16)$ & 0.2659 & $-0.20(-0.62,0.22)$ & 0.3457 \\
\hline \multicolumn{6}{|c|}{${ }^{\dagger} \mathrm{p}<0.05$ in model after correction for multiple comparisons ( $\mathrm{n}=4$ for children $\geq 5$ years of age at enrolment) } \\
\hline \multicolumn{6}{|c|}{1 Linear mixed effects (LME) model where observations within subject were correlated using a subject-specific intercept, and time points as categorical variables } \\
\hline \multicolumn{6}{|c|}{$\begin{array}{l}\text { Models included age, gender, height-for-age z-score, socioeconomic status, home environment, parental education, preschool education of the child (any), } \\
\text { presence of coma, number of seizures during admission, and acute kidney injury }\end{array}$} \\
\hline \multicolumn{6}{|c|}{${ }^{3}$ Planning is assessed in children $\geq 7$ years of age } \\
\hline
\end{tabular}

$\geq 5$ years at the time of the severe malaria episode. However, it is possible that with a larger sample size, some associations seen might have reached statistical significance.

The relationship between Angpt-2 across cognitive domains in children $<5$ years of age but not in children $\geq 5$ years of age is consistent with the 'early vulnerability' perspective showing worse cognitive outcomes after brain injury at an earlier age versus later childhood [30, 31]. These studies suggest that central nervous system (CNS) injury during severe malaria occurring earlier in childhood ( $<5$ years), when cognitive abilities are not yet developed or are developing, results in widespread disruption in function compared to injury in later childhood. In children who were $<5$ years at the time of severe malaria, but $\geq 5$ years of age at testing, Angpt-2 levels were related to worse outcomes in learning and in simultaneous processing, which is related to visual-spatial ability. Thus, children $<5$ years of age with severe malaria show an association of elevated Angpt-2 levels and impaired visual-spatial abilities that persists as they get older. Of note, it is not possible to rule out an association between Angpt-2 and worse cognitive outcomes in older children as the number of children who were $\geq 5$ years of age at severe malaria exposure was limited. The age stratification at 5 years 
in this study reflects the availability of cognitive assessment tools as there was not a single battery that could assess cognition over the entire age range of the study (i.e., 18 months to 12 years). However, the cut-off of 5 years of age is arbitrary and may not accurately reflect periods of age-related vulnerability. Additional studies are needed to understand the long-term impact of age-related susceptibilities in cognition and how early injury relates to long-term deficits.

A relationship between Angpt-2 and blood-brain-barrier dysfunction was previously reported in this cohort of children with CM [21]. Angpt-2 could contribute to cognitive impairment through increases in blood-brainbarrier permeability, leading to increased neuro-active metabolites in the cerebrospinal fluid and consequent brain parenchymal injury [21]. There is also evidence that Angpt-2-integrin interactions can lead to astrocyte and pericyte apoptosis in experimental models of hyperglycaemia $[9,10]$. Both astrocytes and pericytes are involved in active regulation of blood-brain-barrier integrity and loss of either cell type in conjunction with endothelial activation could contribute to blood-brainbarrier dysfunction and neuro-inflammation in malaria (reviewed in [32]). Additional studies are needed to determine whether Angpt-2-integrin interactions contribute to endothelial activation and blood-brain-barrier dysfunction in severe malaria, and whether maturational changes in the blood-brain-barrier explain the Angpt-2 age-related effects observed in this study.

In this cohort, Angpt-2 levels were comparable in children with CM and SMA [21], and in the present study, there were significant associations between Angpt-2 and cognition in children with CM and SMA. These results suggest a common mechanism of brain injury in children with CM and SMA where parasite sequestration in the microvasculature leads to vascular congestion, tissue hypoxia and local inflammatory responses resulting in increased Angpt-2 expression and blood-brain-barrier dysfunction [33]. An increase in vascular permeability may facilitate parasite antigens like histidine-rich protein-2 crossing the blood-brain-barrier [34], resulting in an increase in neuro-inflammation $[35,36]$, neuroactive metabolites [37], and axonal injury [38]. Other bioactive parasite products (i.e., parasite histones) may also contribute to vascular thrombosis and vascular leak [39]. Increased availability of more advanced magnetic resonance imaging (MRI) techniques in low-and-middleincome settings may yield important insights into structural and functional brain changes across the spectrum of uncomplicated malaria, to severe (non-cerebral malaria) and cerebral malaria [40]. Although most radiological studies have been conducted in the context of cerebral malaria [41], a study including adults with non-cerebral severe malaria observed diffuse brain swelling by MRI that was not specific to coma [40], suggesting sub-clinical brain swelling may occur in severe malaria even in the absence of neurological signs. A recent study comparing brain MRI findings with blood-retinal barrier integrity and neurological outcomes identified vascular leak and retinal whitening, a sign of tissue hypoxia, with the development of neurologic deficits in survivors [42]. As Angpt-2 is induced in conditions of hypoxia, sensitizes the endothelium to inflammation and is an important regulator of vascular permeability, these findings lend additional support to vascular dysfunction being a risk factor for increased mortality as well as neurocognitive injury.

\section{Conclusion}

In this prospective, longitudinal study, elevated Angpt-2 was associated with worse neurocognitive outcomes in children across multiple domains when they were exposed to severe malaria at $<5$ years of age, and these associations persisted even after the age of 5 years. No association was seen between Angpt-2 levels and neurocognitive outcomes in children $>5$ years of age at the time of severe malaria admission, but a larger sample size may be required to detect small associations in this age group. A long-term follow-up study is currently underway to evaluate the important question of how findings from early childhood relate to subsequent functioning across different domains (cognition, behaviour, social adjustment, academic, and economic productivity) in later childhood and adulthood.

\section{Abbreviations}

AKl: Acute kidney injury; CNS: Central nervous system; CM: Cerebral malaria; $\mathrm{Cl}$ : Confidence interval; CC: Community children; HIV: Human immunodeficiency virus; IQR: Interquartile range; KABC-2: Kaufmann Assessment Battery for Children 2nd edition; LME: Linear mixed effects; MSEL: Mullen Scales of Early Learning; SD: Standard deviation; SMA: Severe malarial anaemia; WHO: World Health Organization.

\section{Acknowledgements}

We thank the children and their parents who participated in the study, and the study team for their dedicated effort in treating the children and collecting the data.

\section{Authors' contributions}

BJO performed the data analysis and interpretation, and wrote the first draft of the manuscript; ALC performed the sample testing, performed the data analysis and interpretation; JMS contributed to the data analysis and interpretation, and writing of the manuscript, DD contributed to the data interpretation and writing of the manuscript, ROO contributed to the study design, data collection and interpretation, and writing of the manuscript, PB contributed to the study design, data collection and interpretation, and writing of the manuscript, KCK contributed to sample testing, data interpretation, and writing of the manuscript, CCJ designed the primary study, and contributed to data collection, analysis, interpretation and writing of the manuscript. All authors read and approved the final manuscript. 


\section{Funding}

This work was supported by: the National Institute of Neurological Disorders and Stroke; the Fogarty International Center (grants R01NS055349, and D43 NS078280 to (CJ); the Canadian Institutes of Research (FDN-148439 to KCK); and the Canada Research Chairs program (KCK).

\section{Availability of data and materials}

The datasets used and/or analyzed during the current study are available from the corresponding author on reasonable request.

\section{Ethics approval and consent to participate}

Ethical approval was granted by the Institutional Review Boards at Makerere University School of Medicine (Ref: 2008-033, date approved: April 7th 2008), the University of Minnesota (Ref: 0802M27022, date approved: March 31st 2008). The study was approved by the Uganda National Council for Science and Technology (Ref: HS 432, date approved: May 16th 2008). Written informed consent was obtained from parents or guardians of study participants and assent from children $\geq 8$ years of age.

\section{Consent for publication}

Not applicable.

\section{Competing interests}

ALC and KCK are listed as inventors of the following patents (held by University Health Network) involving the use of angiopoietin-1 and -2 as prognostic biomarkers in critical illness: (1) Biomarkers for early determination of a critical or life-threatening response to illness and monitoring response to treatment thereof; (2) Biomarkers for malaria. KCK is also listed as an inventor on the following patents: Angiopoietin-1 and -2 biomarkers for infectious diseases that compromise endothelial integrity. All other authors report no competing interests.

\section{Author details \\ ${ }^{1}$ Department of Medical Microbiology, College of Health Sciences, Makerere University, Kampala, Uganda. ${ }^{2}$ Department of Psychiatry, College of Health Sciences, Makerere University, Kampala, Uganda. ${ }^{3}$ Department of Epidemiol- ogy and Biostatistics, College of Health Sciences, Makerere University, Kam- pala, Uganda. ${ }^{4}$ Ryan White Center for Pediatric Infectious Disease and Global Health, Indiana University School of Medicine, Indianapolis, IN, USA. \\ ${ }^{5}$ Department of Paediatrics and Child Health, Makerere University College of Health Sciences, Kampala, Uganda. ${ }^{6}$ Centre of Tropical Medicine and Global Health, University of Oxford, Oxford, UK. ${ }^{7}$ Department of Medicine, University of Toronto and University Health Network, Toronto, Canada.}

Received: 4 August 2020 Accepted: 11 December 2020

Published online: 06 January 2021

\section{References}

1. WHO. World malaria report 2019. Geneva: World Health Organization; 2019.

2. John CC, Bangirana P, Byarugaba J, Opoka RO, Idro R, Jurek AM, et al. Cerebral malaria in children is associated with long-term cognitive impairment. Pediatrics. 2008;122:e92-9.

3. Idro R, Marsh K, John CC, Newton CRJ. Cerebral malaria: mechanisms of brain injury and strategies for improved neurocognitive outcome. Pediatr Res. 2010;68:267-74.

4. Bangirana P, Opoka RO, Boivin MJ, Idro R, Hodges JS, Romero RA, et al. Severe malarial anemia is associated with long-term neurocognitive impairment. Clin Infect Dis. 2014;59:336-44.

5. Conroy AL, Opoka RO, Bangirana P, Idro R, Ssenkusu JM, Datta D, et al. Acute kidney injury is associated with impaired cognition and chronic kidney disease in a prospective cohort of children with severe malaria. BMC Med. 2019;17:98.

6. Akwii RG, Sajib MS, Zahra FT, Mikelis CM. Role of angiopoietin-2 in vascular physiology and pathophysiology. Cells. 2019;8:471.

7. Fiedler U, Reiss Y, Scharpfenecker M, Grunow V, Koidl S, Thurston G, et al. Angiopoietin-2 sensitizes endothelial cells to TNF-alpha and has a crucial role in the induction of inflammation. Nat Med. 2006:12:235-9.
8. Fiedler U, Scharpfenecker M, Koidl S, Hegen A, Grunow V, Schmidt JM et al. The Tie-2 ligand angiopoietin-2 is stored in and rapidly released upon stimulation from endothelial cell Weibel-Palade bodies. Blood. 2004;103:4150-6.

9. Park SW, Yun J-H, Kim JH, Kim K-W, Cho C-H, Kim JH. Angiopoietin 2 induces pericyte apoptosis via a $3 \beta 1$ integrin signaling in diabetic retinopathy. Diabetes. 2014;63:3057-68.

10. Yun JH, Park SW, Kim JH, Park YJ, Cho CH, Kim JH. Angiopoietin 2 induces astrocyte apoptosis via av $\beta 5$-integrin signaling in diabetic retinopathy. Cell Death Dis. 2016;7:e2101.

11. Yeo TW, Lampah DA, Gitawati R, Tjitra E, Kenangalem E, Piera K, et al. Angiopoietin-2 is associated with decreased endothelial nitric oxide and poor clinical outcome in severe falciparum malaria. Proc Natl Acad Sci USA. 2008;105:17097-102.

12. Lovegrove FE, Tangpukdee N, Opoka RO, Lafferty El, Rajwans N, Hawkes $M$, et al. Serum angiopoietin-1 and -2 levels discriminate cerebral malaria from uncomplicated malaria and predict clinical outcome in African children. PLoS ONE. 2009;4:e4912.

13. Conroy AL, Lafferty El, Lovegrove FE, Krudsood S, Tangpukdee N, Liles WC, et al. Whole blood angiopoietin-1 and -2 levels discriminate cerebral and severe (non-cerebral) malaria from uncomplicated malaria. Malar J. 2009;8:295.

14. Conroy AL, Phiri H, Hawkes M, Glover S, Mallewa M, Seydel KB, et al. Endothelium-based biomarkers are associated with cerebral malaria in Malawian children: a retrospective case-control study. PLoS ONE. 2010;5:e15291.

15. Erdman LK, Dhabangi A, Musoke C, Conroy AL, Hawkes M, Higgins S, et al. Combinations of host biomarkers predict mortality among Ugandan children with severe malaria: a retrospective case-control study. PLoS ONE. 2011;6:e17440.

16. Jain V, Lucchi NW, Wilson NO, Blackstock AJ, Nagpal AC, Joel PK, et al. Plasma levels of angiopoietin-1 and -2 predict cerebral malaria outcome in Central India. Malar J. 2011;10:383.

17. Conroy AL, Glover SJ, Hawkes M, Erdman LK, Seydel KB, Taylor TE, et al. Angiopoietin-2 levels are associated with retinopathy and predict mortality in Malawian children with cerebral malaria: a retrospective casecontrol study. Crit Care Med. 2012;40:952-9.

18. Hanson J, Lee SJ, Hossain MA, Anstey NM, Charunwatthana P, Maude RJ, et al. Microvascular obstruction and endothelial activation are independently associated with the clinical manifestations of severe falciparum malaria in adults: an observational study. BMC Med. 2015;13:122.

19. Conroy AL, Hawkes M, McDonald CR, Kim H, Higgins SJ, Barker KR, et al. Host biomarkers are associated with response to therapy and long-term mortality in pediatric severe malaria. Open Forum Infect Dis. 2016;3:ofw134.

20. Petersen JE, Mkumbaye SI, Vaaben AV, Manjurano A, Lyimo E, Kavishe RA, et al. Plasma Ang2 and ADAM17 levels are elevated during clinical malaria; Ang2 level correlates with severity and expression of EPCRbinding PfEMP1. Sci Rep. 2016;6:35950.

21. Ouma BJ, Ssenkusu JM, Shabani E, Datta D, Opoka RO, Idro R, et al. Endothelial activation, acute kidney injury, and cognitive impairment in pediatric severe malaria. Crit Care Med. 2020;48:e734-43.

22. KDIGO. Clinical practice guideline for acute kidney injury. Kidney Int Suppl. 2012;2:1-138.

23. World Health Organisation. Severe Malaria. Trop Med Int Health. 2014;19(Suppl. 1):7-131.

24. Caldwell BMBR. Home inventory administration manual. 3rd ed. Little Rock: University of Arkansas; 2001.

25. Bangirana P, John CC, Idro R, Opoka RO, Byarugaba J, Jurek AM, et al. Socioeconomic predictors of cognition in Ugandan children: implications for community interventions. PLoS ONE. 2009;4:e7898.

26. Mullen E. Mullen scales of early learning. Circle Pines: American Guidance Services Inc.; 1995.

27. Kaufman AS, Kaufman NL. Kaufman assessment battery for children manual. 2nd ed. Circle Pines: American Guidance Service; 2004.

28. Bangirana P, Seggane M, Allebeck P, Giordani B, John CC, Opoka OR, et al. A preliminary examination of the construct validity of the KABC-II in Ugandan children with a history of cerebral malaria. Afr Health Sci. 2009;9:186-92. 
29. Opoka RO, Bangirana P, Idro R, Shabani E, Namazzi R, John CC. Lack of mortality in 22 children with sickle cell anemia and severe malarial anemia. Pediatr Blood Cancer. 2018;65:e26745.

30. Anderson VA, Spencer-Smith MM, Coleman L, Anderson PJ, Greenham M, Jacobs R, et al. Predicting neurocognitive and behavioural outcome after early brain insult. Dev Med Child Neurol. 2014;56:329-36.

31. Anderson V, Jacobs R, Spencer-Smith M, Coleman L, Anderson P, Williams $J$, et al. Does early age at brain insult predict worse outcome? Neuropsychological implications. J Pediatr Psychol. 2010;35:716-27.

32. Hawkes M, Elphinstone RE, Conroy AL, Kain KC. Contrasting pediatric and adult cerebral malaria: the role of the endothelial barrier. Virulence. 2013;4(6):543-55.

33. Mandriota SJ, Pyke C, Di Sanza C, Quinodoz P, Pittet B, Pepper MS. Hypoxia-inducible angiopoietin-2 expression is mimicked by iodonium compounds and occurs in the rat brain and skin in response to systemic hypoxia and tissue ischemia. Am J Pathol. 2000;156:2077-89.

34. Thakur KT, Vareta J, Carson KA, Kampondeni S, Potchen MJ, Birbeck GL, et al. Cerebrospinal fluid Plasmodium falciparum histidine-rich protein-2 in pediatric cerebral malaria. Malar J. 2018;17:125.

35. John CC, Panoskaltsis-Mortari A, Opoka RO, Park GS, Orchard PJ, Jurek AM, et al. Cerebrospinal fluid cytokine levels and cognitive impairment in cerebral malaria. Am J Trop Med Hyg. 2008;78:198-205.

36. Shabani E, Ouma BJ, Idro R, Bangirana P, Opoka RO, Park GS, et al. Elevated cerebrospinal fluid tumour necrosis factor is associated with acute and long-term neurocognitive impairment in cerebral malaria. Parasite Immunol. 2017;39:e12438

37. Holmberg D, Franzen-Rohl E, Idro R, Opoka RO, Bangirana P, Sellgren CM, et al. Cerebrospinal fluid kynurenine and kynurenic acid concentrations are associated with coma duration and long-term neurocognitive impairment in Ugandan children with cerebral malaria. Malar J. 2017;16:303.

38. Datta D, Conroy AL, Castelluccio PF, Ssenkusu JM, Park GS, Opoka $\mathrm{RO}$, et al. Elevated cerebrospinal fluid tau protein concentrations on admission are associated with long-term neurologic and cognitive impairment in Ugandan children with cerebral malaria. Clin Infect Dis. 2019;70:1161-8.

39. Moxon CA, Alhamdi Y, Storm J, Toh JMH, McGuinness D, Ko JY, et al. Parasite histones are toxic to brain endothelium and link blood barrier breakdown and thrombosis in cerebral malaria. Blood Adv. 2020;4:2851-64.

40. Maude RJ, Barkhof F, Hassan MU, Ghose A, Hossain A, Abul Faiz M, et al. Magnetic resonance imaging of the brain in adults with severe falciparum malaria. Malar J. 2014;13:177.

41. Mohanty S, Benjamin LA, Majhi M, Panda P, Kampondeni S, Sahu PK et al. Magnetic resonance imaging of cerebral malaria patients reveals distinct pathogenetic processes in different parts of the brain. mSphere. 2017;2:e00193-17.

42. MacCormick IJC, Barrera V, Beare NAV, Czanner G, Potchen M, Kampondeni $\mathrm{S}$, et al. How does blood-retinal barrier breakdown relate to death and disability in pediatric cerebral malaria? J Infect Dis. 2020. https ://doi.org/10.1093/infdis/jiaa541 (Online ahead of print).

\section{Publisher's Note}

Springer Nature remains neutral with regard to jurisdictional claims in published maps and institutional affiliations.
Ready to submit your research? Choose BMC and benefit from:

- fast, convenient online submission

- thorough peer review by experienced researchers in your field

- rapid publication on acceptance

- support for research data, including large and complex data types

- gold Open Access which fosters wider collaboration and increased citations

- maximum visibility for your research: over 100M website views per year

At BMC, research is always in progress.

Learn more biomedcentral.com/submissions 